\title{
ESTADO E COMÉRCIO INTERNACIONAL: CONVERGÊNCIAS E DIVERGÊNCIAS
}

\author{
STATE AND INTERNATIONAL TRADE: \\ CONVERGENCES AND DIVERGENCES
}

\author{
Patricia Ayub da Costa" \\ Tânia Lobo Muniz"
}

\begin{abstract}
Resumo: Analisa a evolução histórica do Estado partindo de sua atuação na atividade econômica, considerando o quanto que essa intervenção depende do momento político-econômico vivenciado. Examina a globalização como fenômeno multifacetado que resulta na mundialização do fluxo comercial, surgimento de novos atores internacionais e processo de aceleração da interdependência desses atores. Considera que a divisão de atribuições e a reestruturação do papel Estatal diante do comércio internacional não implicam na crença da desnecessidade deste para o comércio, mas que, pelo contrário, devem convergir em seus interesses para suas próprias manutenções e alcance de seus objetivos de forma equilibrada.
\end{abstract}

Palavras-chave: Estado. Comércio internacional. Globalização. Organizações internacionais.

\begin{abstract}
This work analyses the historical evolution of the State starting from its presence in the economic activity and considering to what extent such an intervention depends on the political-economic context. It examines globalization as a multifaceted phenomenon that results in commercial flow with worldwide proportions, in the emergence of new international actors and in the acceleration process of interdependence of such actors. This paper also considers that the division of attributions and the restructuring of the State's role in international trade does not
\end{abstract}

\footnotetext{
"Mestranda em Direito Negocial na área de concentração Direito e Relações Empresariais e Internacionais da Universidade Estadual de Londrina. Especialista em Direito Empresarial, Fundadora e Diretora Executiva do INPRI - Instituto Paranaense de Relações Internacionais, Advogada e Professora de Direito Internacional.

"Doutora em Direito das Relações Sociais pela PUC/SP, Professora Adjunta do Departamento de Direito Público e do Curso de Mestrado da Universidade Estadual de Londrina.
} 
imply in the belief that it is not necessary for trade; on the contrary, such elements should converge to the State's advantage for its own maintenance and for the achievement of its objectives in a balanced way.

Keywords: State, international trade, Globalization, International organizations.

\section{CONSIDERAÇÕES INICIAIS}

As mudanças no cenário internacional a partir do pós-guerra mundial, como o avanço tecnológico dos transportes e das comunicações, a convivência do multilateralismo com o regionalismo, a intensificação da globalização a partir da década de 80, estreitaram as relações empresariais internacionais ao propiciarem o rompimento de fronteiras para a circulação de mercadorias, serviços, investimentos e pessoas.

Esse movimento acabou repercutindo na soberania dos Estados, limitada pela interdependência comercial e econômica entre si e de outros atores internacionais, como as empresas transnacionais, pelos direitos humanos e por sua participação em organizações internacionais.

Hodiernamente, faz-se uma releitura do Estado e de sua soberania, com um olhar crítico influenciado por questões políticas, sociais, econômicas, culturais e jurídicas. E o direito, como ciência social aplicada, reguladora da sociedade, não pode ficar à deriva dessas mudanças, mas, pelo contrário, deve atender às necessidades do Estado contemporâneo nas relações internacionais, com a finalidade de garantir-lhe estabilidade, bem como a todas as pessoas nele inseridas, sejam naturais ou jurídicas.

Como salienta Tânia Lobo Muniz (2006, p. 156)

Temos que unir o corpo de normas surgidas das relações privadas internacionais com a autoridade dos Estados, cuja busca de interação social, econômica e política visa, principalmente, o aprimoramento da sociedade internacional de uma forma moderna e democrática, na qual predomine a liberdade e independência, e que somente poderá ser garantida pela atuação estatal.

Dessa forma, convém analisar a evolução e as transformações pelas quais tem passado o conceito de Estado na nova ordem econômica internacional, considerando-se a inter-relação com outros atores internacionais, como as empresas transnacionais e as organizações internacionais. 


\section{CONSIDERAÇÕES SOBRE O ESTADO E SUAS TRANSFORMAÇÕES}

O conceito de Estado tem passado por muitas transformações ao longo do tempo, principalmente no que concerne à soberania. Essas transformações foram influenciadas por diversos fatores, dentre eles, o econômico foi primordial.

No Estado Absolutista, a soberania estava centrada no próprio soberano que a possuía de forma absoluta e perpétua. Era um Estado forte com um governante com poderes ilimitados que ditava o Direito e intervinha no domínio econômico. Naquele modelo cabia ao povo apenas obedecer às ordens do soberano. Esse tipo de Estado marcou a passagem dos homens de um estado de natureza para uma convivência em sociedade nos moldes de um contrato social.

No entanto, ao final da Idade Moderna, “o poderio e esplendor dos reis absolutistas opunham-se ao empreendimento burguês, à lucratividade e à capacitação em curso, levando ao processo das revoluções burguesas que, ao derrubar os monarcas absolutistas, inaugurariam o mundo contemporâneo" (VICENTINO, 1997, p. 205).

Ou seja, com a ascensão da burguesia - classe comerciante - fazia-se necessário um Estado mais liberal, que permitisse maior autonomia à classe social que surgia. Não só o povo, mas também o soberano deveriam obedecer à lei para a segurança das relações sociais. Assim, a função do Estado era garantir, por meio de um direito legislado, a vida, a liberdade e a propriedade para que as pessoas pudessem se relacionar e o mercado se auto-regular por sua dinâmica.

O Estado Liberal ressaltava as garantias e liberdades individuais com um papel reduzido socialmente. Daí ser denominado de Estado mínimo que deveria intervir o menos possível e apenas desejável na ordem econômica, com a finalidade de garantir a autonomia privada, o cumprimento dos contratos e a livre concorrência.

No entanto, aos poucos a classe trabalhadora demandou por direitos sociais, não concordando com o tratamento dispensado; aliado a isso, depois da I Guerra Mundial, o capitalismo passou a necessitar de grandes somas de capital e de novos meios para socorrer as economias atingidas pela guerra. Esse cenário contribuiu para uma remodelação das funções Estatais, impensável para o padrão até então existente. (MARQUES NETO, 2002).

Assim, o Estado Social cresce como resposta às debilidades do Estado Liberal. Caracteriza-se como provedor do bem estar social, tem um caráter extremamente intervencionista, inclusive na economia. Com isso, suprime liberdades individuais e estende sua influência a quase todos os domínios que pertenciam à iniciativa 
individual, é o próprio Estado que investe para poder criar condições adequadas para o andamento da atividade produtiva, endividando-se.

A partir da década de 80 intensifica-se o movimento comercial internacional e cresce a competitividade entre os envolvidos nesse comércio, sejam empresas privadas ou estatais. Para se destacar é preciso o investimento em novas tecnologias nas áreas de comunicação, transporte, infra-estrutura, etc. Percebe-se, então, que os custos do modelo estatal voltado para os direitos sociais são demasiadamente pesados, o que dificulta a concorrência, o desenvolvimento econômico em nível global.

Essa percepção permite que esse paradigma de Estado entre em crise, pois não possui recursos para manter a "superestrutura" criada para atender o bem social e acaba perdendo espaço no cenário econômico, abrindo caminho para uma nova era: a da globalização que vem acompanhada de políticas neoliberais.

Atualmente vive-se um novo ciclo do capitalismo ditado pela tecnologia e por novos meios de organização da produção, o que leva alguns a acreditarem que o Estado Nacional não é necessário como elo essencial na estruturação da cadeia produtiva (MARQUES NETO, 2002). Marques Neto (2002, p. 102) explica que, em suma, "peleja-se pela redução ou retirada do Estado de todos os campos em que os atores econômicos possam atuar com maior eficiência ou desejam atuar com ampla liberdade”.

Contudo, como expõe Gilmar Antonio Bedin (2005, p. 82),

[...] uma das primeiras consequiências estruturais do fenômeno da globalização é o declínio do conceito de soberania e a redefinição do papel do Estado soberano na articulação dos acontecimentos humanos. Isto, no entanto, não quer dizer que o Estado moderno deixou de ser, integralmente, uma das mais sólidas instituições políticas do mundo moderno e uma das referências mais relevantes da sociabilidade humana da atualidade. O que é possível afirmar é que o Estado passou a desempenhar novas funções - como auxílio à formação dos blocos econômicos regionais e de fomento à organização e à criação de inteligência artificial - e que adquiriu um novo estatuto, notadamente de um Estado dotado de soberania e autonomia relativas.

Nesse sentido, é fato notório que a soberania do Estado não é absoluta como era no início do Estado moderno, porém, sua flexibilização não retira do Estado sua função de gestor da sociedade nacional e tampouco sua qualidade de sujeito de direito internacional.

Passando-se pela evolução do Estado Absolutista até o Neoliberal, percebese que de uma forma ou de outra sempre houve intervenção no domínio 
econômico, porém, essa intervenção que dita a força soberana do Estado varia conforme a decisão política. Nesse sentido, Fabio Nusdeo (2001) explica que saber o quanto de Estado trata-se de uma opção política da sociedade e ela tenderá a combinar as parcelas de Estado e mercado na medida desejável em determinado momento histórico.

Dessa forma, as transformações do Estado observadas refletem uma necessidade e uma decisão política de, em determinado momento, geralmente acompanhado por fatores ligados à economia, determinar-se o imperativo da intervenção estatal. A grande discussão está em saber quanto do fluxo comercial internacional é determinante no quantum de soberania de um Estado.

\section{COMÉRCIO INTERNACIONAL}

\subsection{Globalização no comércio}

Não só os Estados mudaram; mas as relações comerciais também se intensificaram e mundializaram, ganhando proporções inimagináveis: - o comércio não conhece fronteiras, é real, é virtual, é transnacional. Iniciou sua empreitada nas caravelas e hoje é cibernético. Aproximou pessoas e culturas e consigo trouxe inovações no direito, como o direito comunitário.

A aproximação entre as pessoas, essencialmente no campo comercial e econômico, é uma necessidade humana e acompanha a própria evolução da convivência em sociedade. Entretanto, houve uma intensificação desse processo a partir do pós-guerra, com a criação de blocos comerciais regionais e com as inovações tecnológicas nos mais diversos campos do conhecimento.

Paula Christine Schlee (2004, p. 55) afirma que a globalização

[...] é o conjunto de transformações econômicas, políticas, sociais e culturais, em curso a partir de princípios da década de 1980, ocasionado e facilitado pelo surgimento e desenvolvimento das tecnologias de informação e da desregulamentação dos mercados mundiais de capitais, que resultaram na interligação profunda desses mesmos mercados, com reflexos nos mercados mundiais de bens e serviços e ocasionando uma nova divisão internacional do trabalho.

Contudo, a globalização não é fenômeno recente na história da humanidade, porém, a evolução tecnológica propulsada a partir da década de 1980 foi essencial para que se alcançasse o grau de desenvolvimento e de interdependência hoje existente entre os mais diversos atores internacionais.

Portanto, a emergência do fenômeno da globalização do mundo configura-se como uma grande mudança histórica, caracterizada por uma maior 
interdependência global, em que o centro da articulação da sociedade internacional desloca-se, em boa medida, dos Estados soberanos para os novos atores das relações internacionais (organizações internacionais, empresas transnacionais, organizações não-governamentais, etc.) e passa a se constituir a partir de novos canais de comunicação e de novas referências significativas, não mais nacionais e sim mundiais (BEDIN, 2005, p. 80).

Essas transformações permitem a internacionalização do processo produtivo - a capacidade das empresas de mobilizarem as estruturas de produção para qualquer país a fim de escapar da intervenção estatal no domínio econômico com o nascimento de "fábricas globais", e, por outro lado, com o poder da comunicação de massa, a mundialização do consumo (MARQUES NETO, 2002, p. 106-108).

Jurgen Habermas (apud MARQUES NETO, 2002, p. 108) assinala que

[...] com a internacionalização dos mercados financeiros, de capitais e de trabalho, os governos nacionais têm sentido crescentemente o descompasso entre a limitada margem de manobra de que dispõem e os imperativos decorrentes basicamente não das relações de comércio em nível mundial, mas das relações de produção tramadas globalmente. Estas escapam mais e mais às políticas intervencionistas dos governos.

José Eduardo Faria (apud MARQUES NETO, 2002, p. 109) explica os reflexos desse processo apontando que a "mundialização da economia, mediante a internacionalização dos mercados de insumo, consumo e financeiro”, para se afirmar e expandir, acaba por transpor os limites geográficos das economias nacionais, "limitando crescentemente a execução das políticas cambial, monetária e tributária dos Estados Nacionais”, ou seja, restringindo a própria soberania.

Interessante observar que Montesquieu (apud DAL RI JÚNIOR, 2000) legitimava a expansão do mercado como instituição política, considerando-o elemento propício a limitar o poder absoluto do soberano. Porém, também ponderava que a ambição dos homens poderia levar a abusos. Ainda afirmava que o desenvolvimento do comércio internacional conduziria ao estabelecimento da paz entre as nações, pois as nações que negociassem tornar-se-iam dependentes (apud DAL RI JÚNIOR, 2000). Nesse sentido, entendia Kant que a expansão do comércio conduziria à união pacífica entre os povos (apud DAL RI JÚNIOR, 2000). E, nesse mesmo raciocínio, explica Roberto Di Sena Junior (2006, p. 49), "[... ] sob o ponto de vista teórico, o comércio internacional objetiva promover o bem-estar dos povos através do aumento de sua renda real proporcionada pela expansão do fluxo comercial entre as nações”. 
Nos dias atuais, constata-se que a expansão comercial realmente tornou os Estados economicamente dependentes, porém, a união pacífica entre os povos parece estar ameaçada pelos abusos e opressão dos mais poderosos sobre os mais pobres, pela cobiça e ganância do homem que não tem conseguido dosar a expansão comercial com a própria sustentabilidade de sua vida em seu meio ambiente. Fatores que levam Eduardo Jorge e Luiz Gushiken (apud MARQUES NETO, 2002, p. 105) a defender que

[...] a globalização, mundialização, ou como se queira chamar, é um fato. Um fenômeno irreversível, com efeitos danosos para os mais fracos já há muito denunciados, mas, ao mesmo tempo, com potencialidades positivas capazes de produzir alternativas que nos elevem a um novo patamar civilizatório.

Dessa maneira, a atuação do direito é essencial na regência dessa orquestra formada por atores com especialidades, necessidades e interesses distintos, como os Estados, as empresas transnacionais, as organizações internacionais intergovernamentais e a sociedade civil, para combater os abusos, propiciar o desenvolvimento sustentável e a harmonia nas relações internacionais.

\subsection{Comércio internacional e Direito}

Como se pode perceber, com o passar dos séculos o comércio desenvolveuse e expandiu-se por todas as partes do mundo, de modo que nenhum país hodiernamente possa viver isoladamente. $\mathrm{O}$ intercâmbio de informações, mercadorias e serviços é intenso e quotidiano.

O que é esse comércio internacional? Irineu Strenger (1998, p. 82.) define-o como o conjunto de operações internacionais de finalidade lucrativa realizado por meio de intercâmbio de bens visíveis (mercadorias) ou de negócios invisíveis (referidos a serviços e transações).

Trata-se de ambiente dinâmico, ao qual o direito não pode estar alheio à sua realidade. No entanto, os legisladores e julgadores nacionais têm demonstrado dificuldades em acompanhá-lo devido às suas complexidades e à diversidade de atores e sistemas jurídicos envolvidos.

Assim, embora as diferenças sejam imensas e as legislações internas de cada país queiram regular essas relações, e de certa forma o fazem com o comércio interno, não se pode pensar que os Estados tenham total ingerência no âmbito internacional, porque independente do uso, da língua, da cultura e da religião, o que o empresário pretende (universalmente) é vender, comprar, trocar, lucrar; como a própria história do comércio já demonstrou.

Nesse sentido, explica Irineu Strenger (1996, p. 62) que 
a diversidade dos sistemas existentes e a participação dos Estados nos atos de comércio convenceram os juristas e comerciantes, nessa área, de que as leis nacionais interferem negativamente no crescimento global do comércio e de que há necessidade de desenvolver regras que possam ser aplicadas indistintamente, seja onde for que ocorra uma transação de comércio.

Foi na busca dessa segurança, que não necessariamente provém dos judiciários estatais, mas em geral dos próprios costumes comerciais, que com o decorrer dos anos os profissionais do comércio, as entidades privadas e organismos internacionais formaram um "código de normas e princípios" que os resguardam, independentemente da religião, regime político ou costume da outra parte.

Assim, com o crescimento das atividades empresariais, os comerciantes foram unificando seus usos e costumes para diminuir os conflitos decorrentes de suas diferenças, surgindo a partir daí, o que se denomina atualmente de nova "lex mercatoria" internacional, estabelecendo alguns pilares fundamentais como: os usos profissionais, os contratos-tipo, as regulamentações profissionais ditadas nos limites de cada profissão por suas associações representativas e a jurisprudência, principalmente a arbitral (STRENGER, 1996).

Marcus Baccega (2002) explica que a presente realidade é de um comércio internacional em expansão que paradoxalmente unifica o gênero humano, por não conhecer barreiras políticas ou culturais, e concomitantemente é causa de conflitos, clamando pela presença racional das instâncias de direito internacional público.

Assim, faz-se mister a emergência de um novo arcabouço de Direito Internacional, "em cujo âmbito os processos de elaboração normativa se dão no plano das interdependências sociais e econômicas descentralizadas”, exigindo um novo direito para reger esta sociedade globalizada, com a possibilidade de influenciar o direito interno, como já vem ocorrendo na solução de conflitos, com a arbitragem (MARQUES NETO, 2002, p. 111-2).

Significa que essa estrutura não é só de natureza pública, mas também mercatória. Cabe ressaltar o desempenho eficiente das organizações internacionais no estabelecimento de códigos de normas na tentativa de harmonizar e até mesmo unificar procedimentos e regras internacionais.

\subsection{1 "Lex mercatoria"}

Como visto, as relações econômicas decorrentes das atividades empresariais aos poucos formaram uma regulamentação relativamente independente dos regimes jurídicos estatais, vinculando todos que atuam nesse cenário - a "lex mercatoria”. 
Como fontes da "lex mercatoria" têm-se os usos e costumes, os princípios gerais e as regras emanadas das organizações internacionais e/ou entidades privadas com atuação representativa das comunidades comerciais (STRENGER, 1996).

Destaca-se o intenso trabalho de unificação, consolidação e síntese, ao qual vêm se dedicando várias instituições internacionais:

Esse trabalho constitui-se na edição de leis uniformes, leis-modelos, conjuntos de regras e princípios que regem o comércio internacional, dos quais são exemplos as Leis Uniformes sobre Letras de Câmbio e Notas Promissórias (Genebra, 1930), a Lei Uniforme sobre Cheques (Genebra, 1931), os Incoterms, as Regras e Usos Uniformes de Créditos Documentários, as Regras Uniformes para Garantia de Contratos (CIC), a Lei-Modelo de Arbitragem (UNCITRAL), a Convenção Internacional sobre Compra e Venda Internacional (Viena, 1980), os Princípios dos Contratos Internacionais (UNIDROIT) e a Convenção Interamericana sobre o Direito Aplicável aos Contratos Internacionais (Cidip V - Cidade do México, 1994). (MAGALHÃES; TAVOLARO, 2004, p. 64).

Na doutrina, Irineu Strenger (1996, p. 78) entende como "lex mercatoria” o "conjunto de procedimentos que possibilita adequadas soluções para as expectativas do comércio internacional, sem conexões necessárias com os sistemas nacionais e de forma juridicamente eficaz".

"Pode-se considerar a lex mercatoria como as regras costumeiras desenvolvidas em negócios internacionais aplicáveis em cada área determinada do comércio internacional, aprovadas e observadas com regularidade” (MAGALHÃES; TAVOLARO, 2004, p. 61).

Deve-se alcançar, contudo, que embora haja autonomia da vontade em âmbito normativo internacional expressado, por exemplo, pela "lex mercatoria" ${ }^{\text {, essa }}$ não está "solta" na sociedade sem nenhum tipo de limites, mas pelo contrário, as normas de direito internacional devem ser aplicadas e executadas sob a jurisdição de um Estado e, portanto, não podem contrariar a soberania, a ordem pública e os bons costumes. Pois, não seria possível imaginar norma jurídica sem o suporte de coerção estatal.

\footnotetext{
${ }^{1}$ As regras da lex mercatoria, desenvolvidas no comércio internacional embora nem sempre previstas nos direitos nacionais, não são necessariamente com estes conflitantes, sendo com freqüência compatíveis com os princípios que governam o direito obrigacional. Os tribunais poderão dar-lhe efetividade, seja fundamentados no princípio do pacta sunt servanda e no da boa-fé, seja na sua adequação aos princípios gerais no direito. Somente quando norma de ordem pública local for violada é que os tribunais nacionais estarão compelidos a afastar a aplicação da regra costumeira internacional. (MAGALHÃES; TAVOLARO, 2004, p. 62).
} 
Tem-se, portanto, que essas normas, em algum momento, principalmente quando não forem cumpridas espontaneamente terão que ser aplicadas em algum Estado, caracterizando o vínculo entre si e a legislação interna desse determinado país.

Contudo, visando maior segurança e celeridade, com a evolução comercial, a comunidade empresarial internacional foi apresentando suas próprias normas garantidoras, incluindo em seus contratos verdadeiro sistema sancionador, aceitando a decisão de árbitros e, até mesmo, formando um sistema de sanções indiretas, mas não menos eficazes, que pode se apresentar em forma de lista negra, boicote, não admissão a concorrências, exigência de maiores garantias ou diversas condições de pagamento, que podem deixar fora do mercado o inadimplente (STRENGER, 1996).

Floriano Peixoto Marques Neto (2002) corrobora a posição acima ao afirmar que a "lex mercatoria" é respeitada por estar inserida não só no âmbito dos organismos internacionais, mas na própria relação entre as corporações empresariais privadas.

A importância desse conjunto de normas para as relações comerciais pode ser percebida na exposição de Irineu Strenger (1996, p. 147-148), que acredita ser a única teoria capaz de auxiliar os empresários a atuarem internacionalmente

[...] sem correr o risco de ver-se bloqueado pela contingência do conflito de leis ou até mesmo a ordem pública interna, porquanto está baseada em mecanismos mais flexíveis, que permitem contornar esses impasses, como ocorre com as decisões arbitrais, livremente desenvolvidas e com percentual relativamente pequeno de casos dependentes de execução forçada perante justiças estatais.

Assim, Arnaldo Wald (1994, p. 326-327) alerta que a atitude do jurista brasileiro, no que diz respeito à "lex mercatoria", deve ser de participante ativo de sua construção, pois este novo direito se inspira "nos princípios gerais do sistema jurídico dos países do Ocidente, ao qual pertencemos, pela nossa cultura, pela nossa formação e pelos nossos ideais democráticos, liberais e inspirados na Justiça”.

Desse modo, a nova "lex mercatoria" tem se destacado no cenário comercial internacional, impulsionando-o, garantindo-lhe segurança e meios eficazes para a solução de conflitos sem a intervenção direta do Estado, o que não significa sua exclusão no momento em que for necessária sua aplicação e execução.

\section{A REMODELAÇÃO DO ESTADO ATUAL}

Com a análise das transformações do Estado e do comércio internacional é 
possível sopesar a relação entre os atores internacionais atualmente, inclusive discutindo-se as atribuições do Estado no século XXI.

Nesse cenário internacional, com um comércio internacional em plena expansão e mundializado, questiona-se a própria necessidade do Estado. Elve Miguel Cenci (2008, p. 8) contextualiza a questão

Se tradicionalmente os Estados nacionais estabeleciam claramente as regras de atuação dos atores internos e as relações com os externos, com a globalização essas noções são alteradas. Mesmo os acontecimentos locais sofrem em grau maior ou menor a interferência de fatores externos, basta ver os efeitos da concorrência mundial em certos setores da economia. Decisões tomadas ao redor do mundo pelas grandes corporações influenciam até mesmo decisões governamentais.

Habermas (apud CENCI, 2008, p. 8) explica que a "administração e a legislação nacionais não têm mais um impacto efetivo sobre os atores transnacionais, que tomam suas decisões de investimentos à luz da comparação, em escala global, das condições de produção relevantes”.

Não existe mais fidelidade de agentes econômicos aos Estados, eles vivem em busca de melhores condições para o exercício de seus interesses e para que os Estados mantenham o nível de investimentos é preciso fornecer condições de desenvolvimento a estes atores, principalmente às empresas transnacionais.

Em verdade, há concorrência entre os Estados na busca por investimentos externos em seu território e por sua vez, as empresas transnacionais buscam locais com políticas de governo propícias para rentabilidade de seus negócios.

Os agentes econômicos circulam pelo mundo em busca de melhores oportunidades e cobram dos governos locais condições de infra-estrutura adequadas. Cabe ao Estado fornecer tais condições para que os agentes privados possam competir entre si em escala planetária. Sob o ponto de vista político, ganha eleitoralmente o governante que conseguir guardar a posição, isto é, atrair cada vez mais novos capitais para seu país mesmo que em condições assimétricas de negociação. (CENCI, 2008, p. 9).

Nessa conjuntura, a intervenção do Estado no domínio econômico varia conforme as decisões políticas e as necessidades de mercado. Floriano Peixoto Marques Neto (2002) ensina que os Estados não deixaram de ser atores relevantes, mas passaram a compartilhar o espaço decisório com outros atores, tendo que ora coadjuvá-los, ora compor seus interesses, ora ainda se afirmar coercitivamente.

Conforme Montesquieu (apud DAL RI JÚNIOR, 2000, p. 88-89), o fato de o comércio internacional exigir um certo grau de confiança leva o Estado a estar 
sempre preparado para intervir, regulamentando de modo preciso a economia e o fluxo comercial para evitar atitudes arbitrárias que possam vir a criar restrições sem fundamentos ao comércio.

Porém, as circunstâncias atuais têm levado os Estados à percepção de que não podem por si só resolver os problemas decisivos da ação política ou realizar de forma efetiva um amplo leque de funções públicas. Sozinhos os Estados não têm meios para combater os problemas transnacionais como o cibercrime ou o mercado de exploração sexual, a segurança básica, os direitos humanos, os temas sociais globais, como a proteção do meio ambiente, que devem ser debatidos cooperativamente (PEREIRA, 2006).

Assim, até mesmo em situações em que geralmente os Estados agiriam de forma independente, presencia-se a necessidade de cooperação entre todos os atores internacionais, contando com um papel cada vez mais importante das organizações internacionais.

Para Habermas (apud CENCI, 2008, p. 1), a sugestão perante um mundo que é interdependente e multicultural, seria, nas palavras de Elve Miguel Cenci “a supranacionalidade como a forma mais adequada para normatizar competências que foram tiradas do Estado-nação e evitar que o mercado faça suas próprias regras sem limites."

De acordo com Dupas (apud SCHLEE, 2004, p. 67-68), o cenário atual aponta para a solução no sentido de "um Estado, atuante e catalisador, facilitando, encorajando e regulando os negócios privados" para com isso promover o desenvolvimento. Este deve ser o papel do Estado no século XIX, sem descuidar de sua efetividade quanto a garantir os direitos fundamentais à população.

Assim, o Estado ainda é agente da produção; possui a reserva de exploração de certos meios de transporte, de agências educacionais, de empresas ou atividades que repercutem na estabilidade e segurança das instituições, sempre pautado pela sustentabilidade (VILANOVA, 2003, p. 478). Nas questões menores, referentes às atividades empresariais internacionais, são resolvidas pela "lex mercatoria", e as grandes ficam para as organizações intergovernamentais, formadas pelos Estados.

Portanto, é preciso reconhecer que houve profundas modificações nas funções do Estado em decorrência da globalização e da divisão de atribuições, que antes eram somente suas, com as organizações internacionais e com empresas privadas com poderio econômico, muitas vezes maior que de Estados em desenvolvimento. Porém, isso não representa o fim do Estado, pois este possui relevante papel no cenário internacional e interno diante de seus cidadãos, mas uma reestruturação, adequação, não extermínio. 


\section{O PAPEL DOS NOVOS ATORES INTERNACIONAIS NO EQUILÍBRIO ESTADO x COMÉRCIO}

Partindo-se do pressuposto de que o Estado não deixou de existir, mas apenas vive um momento de readequação por dividir seu espaço decisório com outros atores internacionais, faz-se necessário discutir qual o papel desses novos personagens para se alcançar o equilíbrio e o desenvolvimento sustentável sócioeconômico da humanidade.

Assim, além dos sujeitos de direito internacional, analisa-se também os denominados novos atores internacionais - todos aqueles que influenciam diretamente o desenvolvimento das relações internacionais, mas que não possuem as características para a consideração de sua capacidade, como as empresas transnacionais e a sociedade civil por meio das organizações não-estatais.

As empresas transnacionais destacam-se no comércio internacional, segundo Sklair (apud BEDIN, 2005, p.91), por sua influência na flexibilização da soberania estatal.

Daí, portanto, a importância das empresas transnacionais e a supremacia do mercado como referências centrais da atualidade. É que não podemos esquecer que as empresas transnacionais são o foco das práticas econômicas globalizadas e que se constituem no núcleo de articulação fundamental do sistema de economia-mundo da atualidade. Além disso, estas empresas constituem-se nos principais atores das "práticas ideológico-culturais transnacionais que podem ser encontradas na cultura-ideologia do consumismo [e na supremacia do mercado global como referência principal da sociedade atual]"

É notório que com a globalização os Estados não têm mais condições, de sozinhos, imporem medidas ao mercado, pois já não são os únicos atores internacionais. Embora o ente estatal tenha perdido algumas competências nesse cenário, externo e interno, devido à interdependência entre Estados e/ou outros atores, é possível limitar os impactos negativos do "mercado" e resolver grandes problemas mundiais- como o terrorismo, a destruição do meio ambiente -, por meio de um diálogo entre todos esses atores, enfocando-se a importância das organizações intergovernamentais e as não governamentais.

Dentre as principais organizações governamentais que regem as relações comerciais, tem-se a Organização Mundial do Comércio (OMC), a própria Organização das Nações Unidas (ONU) e a Organização dos Estados Americanos (OEA) no sentido de serem responsáveis pela paz e segurança mundial, elementos essenciais ao bom desenvolvimento comercial, além da 
Comissão das Nações Unidas para o Direito do Comércio Internacional (UNCITRAL) e outras. No entanto, justamente pela participação dos Estados na composição e organização destas entidades é que nasce o problema da continuidade e estabilidade nas tomadas de decisões, uma vez que os governos dos Estados mudam e com eles as políticas comerciais e econômicas.

Nota-se, então, a necessidade de uma participação cada vez mais efetiva das organizações não-estatais, não somente em debates, mas também nas tomadas de decisões das organizações internacionais intergovernamentais, como a Organização Mundial do Comércio.

A atuação de atores não-estatais no sistema internacional é crescente e cada vez mais organizada. $\mathrm{Na}$ área relativa ao comércio internacional, esses "novos" atores inserem-se na dinâmica das relações relativas ao comércio de diversas formas, com grande domínio sobre as técnicas e procedimentos da área. E, esse domínio coloca em questão o monopólio do discurso no sistema internacional pelo Estado, inclusive perante organizações inter-governamentais, como a OMC. (SANCHEZ, 2002, p. 151-152).

As organizações não-governamentais - apesar de estarem sob o manto de um direito interno do Estado onde foram constituídas-, têm ganhado maior destaque no âmbito do sistema internacional de comércio em função de seus objetivos alcançarem atividades de caráter transnacional e por possibilitarem aos cidadãos participarem mais ativamente dos fóruns internacionais. (SANCHEZ, 2002, p. 155).

Essa estrutura demandada requer, realmente, que se desenvolvam formas para um governo global democrático. As estruturas das organizações internacionais, apesar das inovações introduzidas durante o último século, seguem a estrutura clássica das organizações inter-governamentais compostas de apenas um sujeito de direito internacional, qual seja, o próprio Estado. O reconhecimento de outros atores restringe-se ainda a uma cooperação incipiente e que com certeza deve requerer, num futuro próximo, novas concepções do sistema internacional e seus sujeitos. Para tanto, a estrutura dessas organizações, inclusive da OMC, deverá passar pelas reformas necessárias. E, essas reformas e novos processos deverão ser seguidos por toda a comunidade internacional, a fim de que não se provoque um déficit no reconhecimento normativo pelos atores. (SANCHEZ, 2002, p. 168).

Com isso, nota-se que os objetivos e necessidade dos atores comerciais e dos Estados não são tão diametralmente divergentes como se prega, pois ambos precisam conviver de forma equilibrada para alcançarem suas necessidades e seu público: cada cidadão potencialmente consumidor e contribuinte. 
Por isso, torna-se necessária "uma nova concepção da política que abandone a velha dicotomia inter-Estado/intra-Estado e que, reunindo estas duas dimensões, incorpore a diversidade das entidades políticas e dos novos atores públicos e privados que, atuando em diferentes planos, o local, o nacional e o global, dêem uma nova configuração à reflexão sobre a política internacional. (CAMARGO, 1999, apud BEDIN, 2005, p. 93).

Assim, Gilmar Antonio Bedin (2005, p. 93) defende que

Partindo da idéia do declínio da governabilidade estatal e da diminuição da eficiência e da eficácia da ação pública e da crescente complexidade e interdependência do mundo da atualidade, a governança democrática global reconhece que os mercados globais tem sido os verdadeiros árbitros da sociedade internacional atual e que, como saída, deve-se estabelecer um conjunto de regras e procedimentos, visando equilibrar as diferentes forças políticas existentes e viabilização da criação de novas instituições e de novos espaços públicos democráticos.

Importante ressaltar que a sociedade civil também possui em seu favor a força da opinião pública para influenciar os atores do mercado, ou seja, as empresas que atuam no comércio internacional, pois dependem da imagem para a inserção de seus produtos nos mercados consumidores e conseqüentemente para a auferição de lucro.

Dessa forma, se houver uma maior participação da sociedade civil na cobrança de resultados sustentáveis para o comércio internacional, maior será a possibilidade de que esse objetivo se realize, beneficiando ainda uma parceria entre o setor privado investidor e o Estado, o que resulta em qualidade de vida e promoção da dignidade humana ao final, alcançando a tão desejada paz mundial.

Nesse contexto globalizado, é preciso reforçar o papel dos novos atores, cada um dentro de suas potencialidades, na busca de uma relação equilibrada entre o Estado e o comércio internacional.

\section{CONSIDERAÇÕES FINAIS}

Do Estado Absolutista ao Neoliberal muita coisa mudou: o poder do soberano, o direito, a economia, o comércio, a relação de interdependência entre os Estados, o surgimento das organizações internacionais e a influência de empresas transnacionais nas relações empresariais e internacionais.

O fenômeno da globalização, que se intensificou após a década de 1980 com a evolução tecnológica, influenciou a remodelação do Estado que passou a dividir suas atribuições com novos atores internacionais. O comércio tornou-se mais dinâmico e mundializado com a abertura das fronteiras nacionais para as relações empresariais exteriores. 
O direito como ciência social veio regulamentar essas relações, fazendo-o por meio da nova "lex mercatoria" - aplicada principalmente pelos empresários e pelas entidades privadas - e do direito internacional público, destacando-se o papel das organizações intergovernamentais.

Dessa forma, pela menor intervenção estatal no domínio econômico, alguns arriscam que seria o fim do Estado, uma vez que sua soberania estaria limitada aos interesses particulares de outros atores internacionais. Porém, o Estado ainda é importante ator no cenário internacional, embora esteja passando por transformações em seu conceito de soberania, entendendo que compartilhar não significa fraquejar, bastando mirar-se pelo exemplo da União Européia e do direito comunitário.

Vive-se um mundo em constante reestruturação, um comércio em expansão, um direito em evolução, um Estado em readequação. Evidente, porém, que ainda cabe ao Estado zelar por seus cidadãos, garantindo-lhes segurança e bem estar social.

Como acreditavam Montesquieu e Kant, a expansão do comércio deve levar à interdependência e conseqüentemente à paz. Porém, antes, é preciso entender que o Estado e o comércio devem convergir em seus interesses, pois sem investimentos e fluxo comercial o Estado seria levado ao caos econômico, ao mesmo tempo em que, por sua vez, para que haja comércio é preciso que exista mercado e sem estabilidade estatal não há consumo.

Assim, Estado e comércio devem alinhar seus interesses para que se alcance desenvolvimento, tendo como aliados os novos atores internacionais, como as organizações não-estatais formadas pela sociedade civil que precisa participar mais ativamente dessas transformações, uma vez que qualquer decisão na seara internacional influencia diretamente suas vidas.

\section{REFERENCIAS}

BACCEGA, Marcus. O comércio, suas funções e sua relevância para o direito internacional público. AMARAL JÚNIOR, Alberto (Coord.). Direito do comércio internacional. São Paulo: Juarez de Oliveira, 2002.

BEDIN, Gilmar Antonio. Globalização e suas conseqüências estruturais: potencialidades e desafios. Revista de integração latino-americana, Santa Maria, ano 1, n. 2, p. 77-98, jul./dez. 2005.

CENCI, Elve Miguel. Globalização, Estado-nação e regimes supranacionais. Disponível em: <http://www.conpedi.org/manaus/arquivos/anais/campos/ elve_miguel_cenci.pdf $>$. Acesso em: 31 jan. 2008. 
DAL RIJÚNIOR, Arno. História do direito internacional; comércio e moeda; cidadania e nacionalidade. Florianópolis: Fundação Boiteux, 2004.

DI SENA JÚNIOR, Roberto. Comércio internacional \& globalização: a cláusula social na OMC. 1 ed., 3 tir. Curitiba: Juruá, 2006.

MAGAlHÃES, José Carlos de; TAVOLARO, Agostinho Tofolli. Fontes do direito do comércio internacional: a lex mercatoria. In: AMARAL, Antonio Carlos Rodrigues do (Coord.). Direito do comércio internacional: aspectos fundamentais. São Paulo: Aduaneiras, 2004.

MARQUES NETO, Floriano Peixoto de Azevedo. Regulação estatal e interesses públicos. São Paulo: Malheiros, 2002.

MUNIZ, Tânia Lobo. Arbitragem no Brasil e a Lei 9.307/96. 6 ed. Curitiba: Juruá, 2006.

NUSDEO, Fábio. Curso de economia: introdução ao direito econômico. São Paulo: Ed. Revista dos Tribunais, 2001.

PEREIRA, Juan Pablo Fernández. La seguridad humana. Barcelona: Ariel, 2006.

SANCHEZ, Michelle Ratton. Atores não-estatais e sua relação com a Organização Mundial do Comércio. In: AMARAL JÚNIOR, Alberto (Coord.). Direito do comércio internacional. São Paulo: Juarez de Oliveira, 2002.

SCHLEE, Paula Christine. Política e globalização econômica: o relacionamento Estado-empresas transnacionais. In: CAUBET, Christian Guy (Coord.). A força e o direito nas relações internacionais: as repolarizações do mundo. Florianópolis: Fundação Boiteux, 2004.

STRENGER, Irineu. Contratos internacionais do comércio. 3 ed., São Paulo: LTr, 1998.

. Direito do comércio internacional e Lex Mercatoria. São Paulo: LTr, 1996.

VICENTINO, Cláudio. História geral. São Paulo: Scipione, 1997.

VILANOVA, Lourival. Escritos jurídicos e filosóficos. São Paulo: Axis Mundi: IBET, 2003. v. 2.

WALD, Arnaldo. Algumas aplicações da Lex Mercatoria aos contratos internacionais realizados com empresas brasileiras. In: BAPTISTA, Luiz Olavo; HUCK, Hermes Marcelo; CASELLA, Paulo Borba (Coord..). Direito e comércio internacional: tendências e perspectivas: estudos em homenagem ao Prof. Irineu Strenger. São Paulo: LTr, 1994. 
